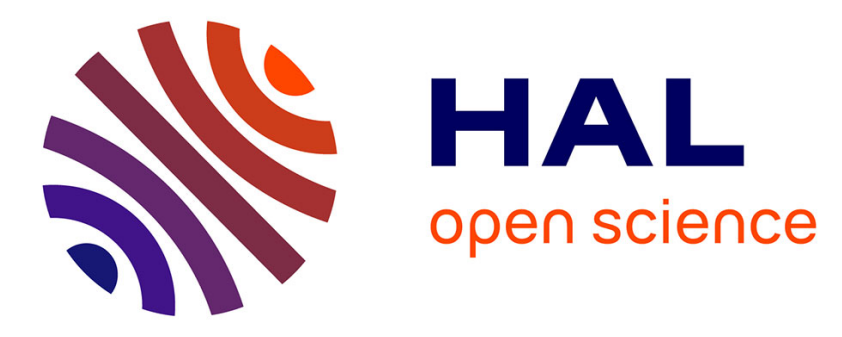

\title{
Thermomechanical characterization of an amylose-free starch extracted from cassava (Manihot esculenta, Crantz)
}

Adriana Pulido Diaz, Denis Lourdin, Guy Della Valle, Alejandro Fernandez Quintero, Hernan Ceballos, Thierry Tran, Dominique Dufour

\section{To cite this version:}

Adriana Pulido Diaz, Denis Lourdin, Guy Della Valle, Alejandro Fernandez Quintero, Hernan Ceballos, et al.. Thermomechanical characterization of an amylose-free starch extracted from cassava (Manihot esculenta, Crantz). Carbohydrate Polymers, 2017, 157, pp.1777-1784. 10.1016/j.carbpol.2016.11.058 . hal-01603936

\section{HAL Id: hal-01603936 \\ https://hal.science/hal-01603936}

Submitted on 2 Jul 2018

HAL is a multi-disciplinary open access archive for the deposit and dissemination of scientific research documents, whether they are published or not. The documents may come from teaching and research institutions in France or abroad, or from public or private research centers.
L'archive ouverte pluridisciplinaire HAL, est destinée au dépôt et à la diffusion de documents scientifiques de niveau recherche, publiés ou non, émanant des établissements d'enseignement et de recherche français ou étrangers, des laboratoires publics ou privés.

\section{(ㅇ)(1) $\$$}

Distributed under a Creative Commons Attribution - NonCommercial - NoDerivatives 44.0 


\section{承ClAT \\ International Center for Tropical Agriculture \\ Since 1967 / Science to cultivate change}

\section{CIAT Research Online - Accepted Manuscript}

\section{Thermomechanical characterization of an amylose-free starch extracted from cassava (Manihot esculenta, Crantz)}

The International Center for Tropical Agriculture (CIAT) believes that open access contributes to its mission of reducing hunger and poverty, and improving human nutrition in the tropics through research aimed at increasing the eco-efficiency of agriculture.

CIAT is committed to creating and sharing knowledge and information openly and globally. We do this through collaborative research as well as through the open sharing of our data, tools, and publications.

\section{Citation:}

Pulido Diaz, Adriana; Lourdin, Denis; Della Valle, Guy; Fernandez Quintero, Alejandro; Ceballos, Hernán; Tran, Thierry; Dufour, Dominique. 2016. Thermomechanical characterization of an amylose-free starch extracted from cassava (Manihot esculenta, Crantz). Carbohydrate Polymers In press.

Publisher's DOI:

http://dx.doi.org/doi:10.1016/j.carbpol.2016.11.058

Access through CIAT Research Online:

http://hdl.handle.net/10568/77842

Terms:

(C) 2016. CIAT has provided you with this accepted manuscript in line with CIAT's open access policy and in accordance with the Publisher's policy on self-archiving.

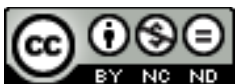

This work is licensed under a Creative Commons Attribution-NonCommercial-NoDerivatives 4.0 International License. You may re-use or share this manuscript as long as you acknowledge the authors by citing the version of the record listed above. You may not change this manuscript in any way or use it commercially.

For more information, please contact CIAT Library at CIAT-Library@cgiar.org. 


\section{Accepted Manuscript}

Title: THERMOMECHANICAL CHARACTERIZATION OF AN AMYLOSE-FREE STARCH EXTRACTED FROM

CASSAVA (Manihot esculenta, Crantz)

Author: Adriana Pulido Diaz Denis Lourdin Guy Della Valle Alejandro Fernandez Quintero Hernán Ceballos Thierry Tran

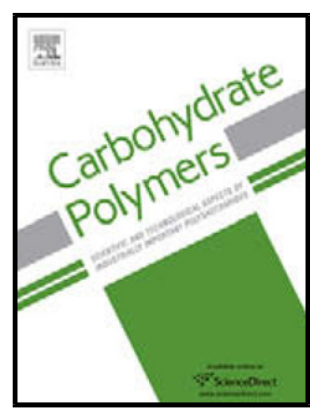

Dominique Dufour

PII:

DOI:

Reference:

To appear in:

Received date:

Revised date:

Accepted date:
S0144-8617(16)31333-9

http://dx.doi.org/doi:10.1016/j.carbpol.2016.11.058

CARP 11770

Please cite this article as: Pulido Diaz, Adriana., Lourdin, Denis., Della Valle, Guy., Fernandez Quintero, Alejandro., Ceballos, Hernán., Tran, Thierry., \& Dufour, Dominique., THERMOMECHANICAL CHARACTERIZATION OF AN AMYLOSE-FREE STARCH EXTRACTED FROM CASSAVA (Manihot esculenta, Crantz).Carbohydrate Polymers http://dx.doi.org/10.1016/j.carbpol.2016.11.058

This is a PDF file of an unedited manuscript that has been accepted for publication. As a service to our customers we are providing this early version of the manuscript. The manuscript will undergo copyediting, typesetting, and review of the resulting proof before it is published in its final form. Please note that during the production process errors may be discovered which could affect the content, and all legal disclaimers that apply to the journal pertain. 


\section{THERMOMECHANICAL CHARACTERIZATION OF AN AMYLOSE-FREE}

\section{STARCH EXTRACTED FROM CASSAVA (Manihot esculenta, Crantz)}

Adriana Pulido Diaz ${ }^{a^{*}}$; Denis Lourdin ${ }^{b}$; Guy Della Valle ${ }^{b}$; Alejandro Fernandez Quintero ${ }^{a}$; Hernán Ceballos ${ }^{c}$; Thierry Tran ${ }^{c, d, e}$; Dominique Dufour ${ }^{c, d, e}$

a) Universidad del Valle, Univalle, Ciudad Universitaria - Meléndez, A.A.25360, Cali, Colombia

b) UR1268 Biopolymères Interactions Assemblages, INRA, 44300 Nantes, France

c) International Center for Agriculture Tropical (CIAT), A. A. 6713, Cali, Colombia

d) Centre de Coopération Internationale en Recherche Agronomique pour le Développement (CIRAD), UMR Qualisud, 34090 Montpellier Cedex 05, France

e) CIRAD, UMR Qualisud, Cali, Colombia

\footnotetext{
${ }^{*}$ Corresponding author at: Escuela Ingeniería de Alimentos Edificio 338, Universidad del Valle, Cali, Colombia
}

Tel.: +(57) 3107964618; fax: +(57) 3212100 .

E-mail addresses: adriana.pulido@correounivalle.edu.co (A. Pulido); Denis.Lourdin@nantes.inra.fr (D. Lourdin); guy.dellavalle@nantes.inra.fr (G. Della Valle) alejandro.fernandez@correounivalle.edu.co (A. Fernandez); h.ceballos@cgiar.org (H. Ceballos); thierry.tran@cgiar.org (T. Tran); d.dufour@cgiar.org (D. Dufour). 
Highlights

Thermal transitions measurements were made by DSC and DMTA.

Thermal behaviors of waxy cassava follow the Flory Huggins theory.

Waxy cassava starch has phase transitions similar to a waxy corn starch. 


\begin{abstract}
The aim of this study was to determine and compare the melting $\left(T_{m}\right)$, glass transition $\left(T_{g}\right)$ and mechanical relaxation $\left(T_{\alpha}\right)$ temperatures of a new waxy cassava starch. Thermal transitions measurements were obtained by Differential Scanning Calorimetry (DSC) and Dynamical Mechanical Thermal Analysis (DMTA). The experimental data showed a high correlation between water volume fraction and melting temperature $\left(T_{m}\right)$ indicating that the Flory-Huggins theory can be used to describe the thermal behavior of this starch. The $T_{m}$ of waxy cassava starch-water mixes were lower than a waxy corn starch-water reference system, but differences were not statistically significant. The mechanical relaxation temperatures taken at $\tan \delta$ peaks were found $29-38^{\circ} \mathrm{C}$ larger than $T_{g}$. The $T_{\alpha}$ and $T_{g}$ measured for waxy cassava starch exhibited similar properties to the ones of waxy corn starch, implying that waxy cassava starch can be used in food and materials industry.
\end{abstract}

Keywords: Amylopectin; Phase transitions; Melting ; X-ray diffraction ; extrusion ; heat capacity change 


\section{Introduction}

Cassava native starch shows amylose contents between $15-25 \%$ depending on cultivars and growth conditions (Sánchez et al., 2009), its functional properties are similar to those of waxy (amylose-free) corn starch, with minor differences in gel formation capacity and flavor (Breuninger, Piyachomkwan, \& Sriroth, 2009). Transgenic genotypes (from TMS60444 and Adira 4 of African and Indonesian origin, respectively) producing low amylose starch have been obtained through inhibition of the enzyme (GBSSI) responsible for the amylose synthesis these new (Koehorst-van Putten et al., 2012; Zhao, Dufour, Sánchez, Ceballos, \& Zhang, 2011). The discovery of a waxy starch cassava (AM206-5 clone), is the product of a spontaneous mutation identified after self-pollinating a large number of accessions from the germplasm collection (Ceballos et al., 2007). Additional sources of waxy starch in cassava have recently been reported (Morante et al. 2016). This starch has $0 \%$ of amylose, high crystallinity (40\%), more organized structure (Rolland-Sabaté et al., 2013) and similar properties to waxy corn starch (Rolland-Sabaté et al., 2012).

Phase transitions such as melting are important parameters in starches since they explain aspects of their behavior in food products subject to heat treatments (Núñez, Sandoval, Müller, Della Valle, \& Lourdin, 2009). The thermal characterization of starches was developed primarily using Differential Scanning Calorimetry (DSC) (Biliaderis, Page, Maurice, \& Juliano, 1986; Contreras-Gallegos, Domínguez-Pachecho, Hernández -Aguilar, \& Carballo-Carballo, 2015; Cruz-Orea, Pitsi, Jamée, \& Thoen, 2002). The transitions associated to the melting have shown one or two endotherms (P1 and P2) at different moisture contents for starches of different botanical origin (Biliaderis, 2009; Donovan, 1979; Garcia et al., 1996; Núñez et al., 2009).

Under the Flory-Huggins theory for semicrystalline polymers, Donovan and Lelievre described the melting as a process that presents itself in equilibrated conditions (Lelievre, 1974). However, other authors have stated that these starch 
phase transitions are processes in no equilibrium controlled by the glass transition of the amorphous domains. Despite some limitations identified in this theory, the Flory-Huggins analysis can be used to simulate the thermal behavior in practical applications such as extrusion and baking (Núñez et al., 2009).

The glass transition is a second order thermodynamic phenomenon, known as a physical change of the amorphous zones from a vitreous condition (state) to a viscous rubbery fluid (Slade and Levine, 1993). Therefore, glass transition temperature $\left(T_{g}\right)$ controls, to some degree, time-dependent physical changes as structural and textural transformations. $T_{g}$ value is dependent on composition, thermal history, molecular weight and techniques used (Biliaderis, 1991; Roos \& Karel, 1991; Roos \& Jouppila, 2003; Slade \& Levine, 1993).

The conventional methods to evaluate $T_{g}$ (DSC and dynamic mechanical thermal analysis - DMTA) were used for this study. Other techniques (like nuclear magnetic resonance, electric spectroscopy spin resonance dielectric spectroscopy, dynamic rheometry, inverse gas chromatography, among others) are available but were not used here (Abiad, Carvajal, \& Campanella, 2009; Blanshard, 1995).

The first attempt to predict $T_{g}$ was made by Van den Berg in 1981. $T_{g}$ on native and pregelatinized wheat starch with water contents between $13-22 \%$ has been reported (Roos, 1995; Zeleznak \& Hoseney, 1987). Extrapolated values for anhydrous starch, maltooligosaccharides, amylose and amylopectin have been estimated (Orford, Parker, Ring, \& Smith, 1989). The latest research has focused on starch mixes and plasticizers of interest to the food industry. $T_{g}$ evolution during the storage or its effect in different processes has been explored (Chaudhary, Adhikari, \& Kasapis, 2011; Farahnaky, Farhat, Mitchell, \& Hill, 2009; Sandoval, Nuñez, Müller, Della Valle \& Lourdin, 2009; García, Famá, Dufresne, Aranguren, \& Goyanes, 2009; Guo, Liang, \& Du, 2011; Homer, Kelly, \& Day, 2014).

The main objective of this study was to determine the phase transitions associated with the melting and glass transition temperatures of a new waxy cassava starch (WXCS) with different water contents and in comparison with a waxy corn starch 
(WXMS). This information is useful to continue exploring new applications of this new cassava starch in the food and materials industries.

\section{Materials and methods}

2.1. Materials and samples preparation

\subsubsection{Native starches}

Cassava roots were obtained from clone AM206-5, grown at the International Center for Agriculture Tropical (CIAT, Palmira, Colombia; $3^{\circ} 30^{\prime} \mathrm{N}, 7^{\circ} 21^{\prime} \mathrm{W}$; average annual rainfall: $1021 \mathrm{~mm}$; Altitude: $1000 \mathrm{~m} . a . s . l$; average annual temperature: $26^{\circ} \mathrm{C}$ ). Plants were harvested 17 months after planting. A typical (semi-industrial) process used by small-scale fermented cassava starch facilities (known locally as "rallanderías") was used for extraction (Da et al., 2013; Tran et al., 2015) and preparation of WXCS. WXMS samples were donated by Ingredion ${ }^{\circledR}$ industries (Cali, Colombia). Sampling of starch took place by the quartering method. The moisture contents of native WXCS and WXMS were $11.8 \pm 0.2 \%$ and $10.8 \pm 0.1 \%$ wet weight basis, respectively. The physicochemical (Ceballos et al., 2007), structural (Rolland-Sabaté et al., 2012), molecular and supramolecular (Rolland-Sabaté et al., 2013) characterizations of WXCS have already been reported.

\subsubsection{Preparation of gelatinized starch films}

Native starches were mixed with distilled water to adjust their moisture content to $30 \%$, wet weight basis. The starches were then placed in a plate mold $(100 \times 100$ $x 0.53 \mathrm{~mm}$ ) within a molding press with two heating plates (Pinette, France), and gelatinized at 170 bar and $135 \pm 2{ }^{\circ} \mathrm{C}$ for $6 \mathrm{~min}$. The films were then stored under different controlled relative humidity atmospheres $\left(\mathrm{K}_{2} \mathrm{CO}_{3}, \mathrm{NaBr}, \mathrm{CuCl}_{2}, \mathrm{KCl}, \mathrm{BrCl}_{2}\right)$ for 19 days at $25{ }^{\circ} \mathrm{C}$. The equilibrium moisture contents after 19 days were measured by thermogravimetric analysis with a heating rate of $10^{\circ} \mathrm{C} \cdot \mathrm{min}^{-1}$ up to $130{ }^{\circ} \mathrm{C}$ and holding 30 minutes. The equilibrium moisture contents were: $10.0 \pm$ 
$0.1 \%\left(\mathrm{~K}_{2} \mathrm{CO}_{3}\right), 11.2 \pm 1.0 \%(\mathrm{NaBr}), 12.9 \pm 0.4 \%\left(\mathrm{CuCl}_{2}\right), 14.5 \pm 0.2 \%(\mathrm{KCl}), 16,4 \pm$ $0.2 \%\left(\mathrm{BrCl}_{2}\right)$ (cassava starch films) and $10.5 \pm 0.7 \%\left(\mathrm{~K}_{2} \mathrm{CO}_{3}\right), 11.9 \pm 0.2 \%(\mathrm{NaBr})$, $13.4 \pm 0.5 \%\left(\mathrm{CuCl}_{2}\right), 15.2 \pm 0.9 \%(\mathrm{KCl}), 16.8 \pm 0.3 \%\left(\mathrm{BrCl}_{2}\right)$ (corn starch films).

2.2. Methods

\subsubsection{Crystallinity}

An X-ray diffraction machine model X'Pert PRO ALPHA1 (PANalytical, USA) was used to analyze crystallinity. Native starch powders were exposed to X-ray beams ( $\mathrm{Cu}$ Ka radiation $\lambda=1.5405 \AA$ ) of $45 \mathrm{kV}$ y $40 \mathrm{mV}$, divergence and scattering openings $=0.125^{\circ}$, receiving opening was $0.10 \mathrm{~mm}$, the $2 \theta$ angle was scanned over a range of $5^{\circ}$ to $30^{\circ}$, with a step of $0.02^{\circ}$. The data were normalized by subtracting empty holder background with software Match! $2^{\circledR}$ (Crystal Impact $\mathrm{GbR}$ ) and smoothened by the method developed by Savitsky-Golay in 1964. The relative crystallinity was estimated as the total area of the peaks in relation to the total surface of the diffractogram (Nara \& Komiya, 1983; Wang, Bogracheva, \& Hedley, 1998).

2.2.2. Thermal properties: Gelatinization and Melting of native starch powders

Starch-water solutions were prepared with a $1: 3(\mathrm{w} / \mathrm{v})$ ratio in stainless steel pans (100 $\mu \mathrm{l}-30$ bar). A Perkin Elmer Pyris 6 with nitrogen as purge gas $\left(20 \mathrm{ml}^{\mathrm{min}} \mathrm{m}^{-1}\right)$ DSC equipment was used. Calibration was done with Indium $\left(156.4^{\circ} \mathrm{C}<\mathrm{T}_{0}<156.8^{\circ} \mathrm{C}, 28.2 \mathrm{~J}^{-1} \mathrm{~g}^{-1}<\Delta \mathrm{H}<28.7 \mathrm{~J} . \mathrm{g}^{-1}\right)$. The pans were heated from 15 to $120{ }^{\circ} \mathrm{C}$ at a heating rate of $10^{\circ} \mathrm{C} \cdot \mathrm{min}^{-1}$, using an empty stainless steel pan as reference. All measurements were done in duplicate.

In order to obtain WXCS and WXMS starches with moisture between 8-15 (\% w/w) for melting curves, samples were conditioned for 2 weeks in controlled relative humidity environments generates by saturated salts $\left(\mathrm{LiCl}, \mathrm{MgCl}_{2}, \mathrm{NaBr}, \mathrm{NaCl}\right)$. To reach moisture ranges between 20-50 (\% w/w) starches were hydrated by adding water drop by drop with constant agitation. Water contents were checked by 
thermogravimetric analysis (Q50 TGA, TA Instrument). Thermograms were obtained in a Q100 DSC (TA Instrument), previously calibrated with Indium (Tm:

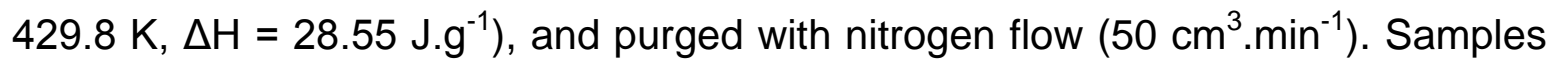
of approximately $12 \pm 0.4 \mathrm{mg}$ were weighed (XS104, Mettler Toledo) in highpressure stainless steel pans (100 bar - $30 \mu \mathrm{l}$ ) and sealed hermetically, each sample was heated from 10 to $230^{\circ} \mathrm{C}$ with a heating rate of $3{ }^{\circ} \mathrm{C} \cdot \mathrm{min}^{-1}$. Universal Analysis $2000^{\circledR}$ software was used to calculate the enthalpy change $(\Delta \mathrm{H})$ and melting temperatures at start $\left(T_{0}\right)$, peak $\left(T_{p}\right)$ and final $\left(T_{m}\right)$. Since some endotherms overlapped under the measurement conditions, a mathematical deconvolution curve fitting technique was used to separate the peaks (Liu et al., 2006).Standard error estimation (SEE) and relative standard deviation (RSD) were estimated. The water volumetric fraction was obtained by (Donovan, 1979):

$$
v=\frac{M C}{M C+\frac{1-M C}{\rho}}
$$

where $M C$ is the fraction moisture content (w.b), $\rho$ : granular starch density, taken equal to 1.5. All measurements were done in duplicate.

2.2.3 Glass transition of gelatinized starch films (prepared as indicated in 2.1.2).

(i) Differential scanning calorimetry (DSC)

Gelatinized starch films (19 $\pm 0.5 \mathrm{mg})$ were weighed (XS104, Mettler Toledo) in aluminum pans $(40 \mu \mathrm{l})$ and sealed hermetically. Each sample was heated from 10 to $120^{\circ} \mathrm{C}$ at $3^{\circ} \mathrm{C} \cdot \mathrm{min}^{-1}$ following by a cooling to $10^{\circ} \mathrm{C}$. Finally, a second heating took place under the same conditions as the first one and $T_{g}$ was calculated as the middle point in the heat capacity change (second cycle). Measurements were taken in duplicate.

(ii) Dynamic Mechanical Thermal Analysis (DMTA)

The measurements took place in an equipment model DMA50N-01dB (Metravib, France $)$. The starch films $(20 \times 10 \times 0.53 \mathrm{~mm})$ samples were coated with Teflon ${ }^{\circledR}$ 
grease (Super Lube) to limit dehydration at high temperatures and then placed in a tension clamp and oscillated at a frequency of $1 \mathrm{~Hz}$. Strain amplitude was maintained at $0.1 \%$ with a heating rate of $3^{\circ} \mathrm{C} \cdot \mathrm{min}^{-1}$ and up to $140{ }^{\circ} \mathrm{C}$. Mechanical relaxation temperatures $\left(T_{\alpha}\right)$ associated to $T_{g}$ were determined from (1) the inflection point of the storage modulus ( $\left.E^{\prime}\right)$ and (2) the peak in $\tan \delta$. Three samples of each material were measured and $T_{\alpha}$ values were averaged.

Statistical analysis

Statistical analysis was done with Statgraphics Centurion $\mathrm{XVI}^{\circledR}$ (Statpoint Technologies Inc). The means were compared with Least Significant Difference tests (LSD) at a significance level $p<0.05$.

\section{Results and discussion}

\subsection{Crystallinity}

Native waxy cassava starch (WXCS) exhibited a mixture of $A$ and $B$ type crystallites (Figure 1a) with smaller peaks at $2 \theta$ angles $8^{\circ}$ and $26.5^{\circ}$, and larger peaks at $15^{\circ}, 18^{\circ}$ and $23^{\circ}$. Type $A$ crystallites were predominant. These observations were in agreement with previous research (Rolland-Sabaté et al., 2013). Native waxy maize starch (WXMS) showed only A type crystallites, a typical characteristic of cereal starches (Zobel, 1988).

The level of crystallinity of WXCS (40\%) was similar to the one reported by Rolland-Sabaté et al., (2012). However it was lower than genetically modified waxy cassava starch (49\%) which had a 6\% amylose content (Gomand et al., 2010). There have also been reports of crystallinity ranges between 38 and $40 \%$ for cassava starches with amylose content ranging between 17 and $21 \%$ (Nuwamanya, Baguma, Emmambu, \& Patrick, 2009: Rolland-Sabaté et al., 2012; 2013). 
The crystallinity of WXMS (39\%) was similar to the one reported in previous works (Cai \& Shi, 2010; Cheetham \& Tao, 1998). Low reflections at $2 \theta 9.9^{\circ}$ and $11.2^{\circ}$ were observed on diffractogram. Also strong reflections at $15^{\circ}$ and $18^{\circ}$ and various peaks over $23^{\circ}$ were detected (Figure $\left.1 \mathrm{~A}\right)$.
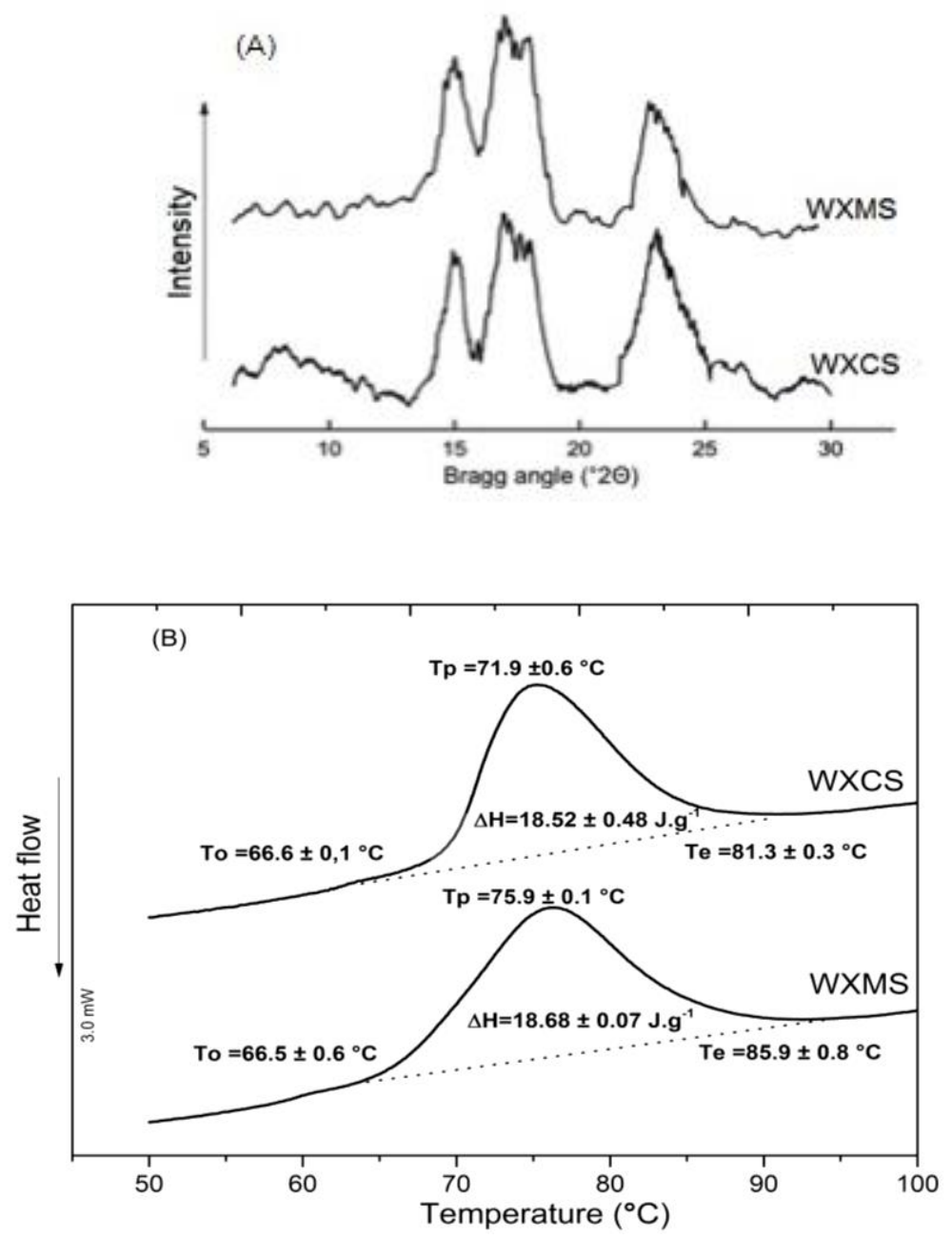

Figure 1. (A) X-rays diffractograms and (B) DSC gelatinization curves for waxy starches: cassava (WXCS) and maize (WXMS). 


\subsection{Gelatinization and Melting}

In excess water, the two native starches (Figure 1A \& 1B) had an onset gelatinization temperature $\left(T_{0}\right)$ about $66.6{ }^{\circ} \mathrm{C}$ without significant differences. However, the peak $\left(T_{p}\right)$ and end $\left(T_{e}\right)$ temperatures showed significant differences. This behavior may be explained by the hydration, swelling and destruction processes of the WXCS granule which were faster compared with WXMS.
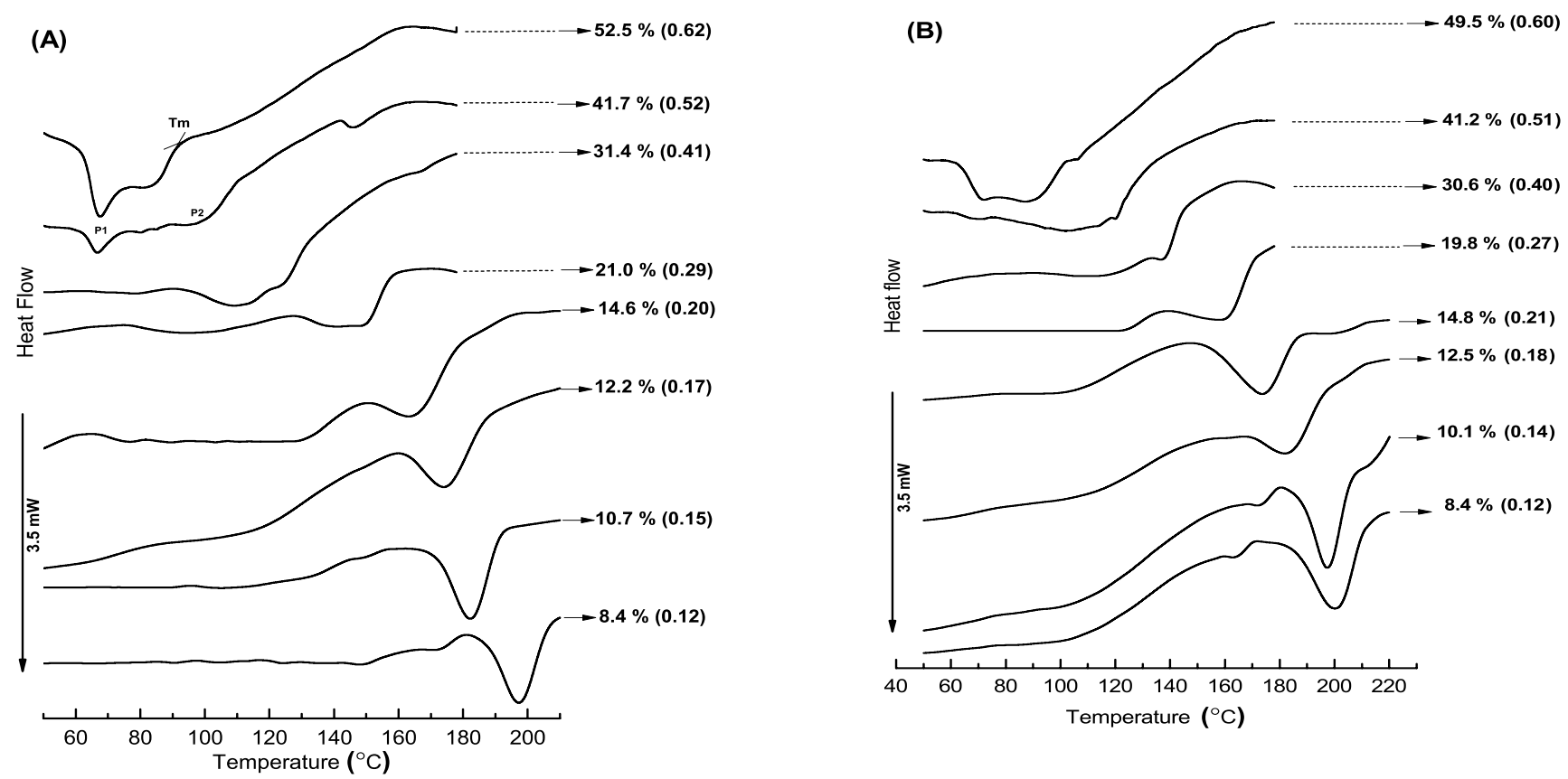

Figure 2. Gelatinization thermograms of waxy cassava (A) and waxy maize (B) starches at different moisture contents $(\% \mathrm{w} / \mathrm{w})$. Water volumetric fraction is shown in parentheses on the graphs. Heating rate: $3^{\circ} \mathrm{C} \cdot \mathrm{min}^{1}$.

Lower $T_{p}$ and $T_{e}$, i.e. a narrower gelatinization peak, can also indicate a more homogeneous size distribution of the starch granules and crystallites within them. The gelatinization enthalpies $(\Delta \mathrm{H})$ are related to the net energy required to complete the swelling, melting of crystallites (endothermic event), hydration and reordering (exothermic event). In this study the $\Delta \mathrm{H}$ of both waxy starches varied around $18.6 \mathrm{~J} . \mathrm{g}^{-1}$ and averages were not statistically different. 
For WXCS, the $T_{0}, T_{p}, T_{e}, \Delta H$ values were slightly higher to the ones described for the same source (Ceballos et al., 2007; Rolland-Sabaté et al., 2012). This difference can be due to the age of the plants harvested for this study, ordinary seasonal environmental variation, or slight changes in the extraction process (Moorthy, 2004). The WXCS and WXMS gelatinization enthalpies had the same values. They were greater than those measured on cassava starches with amylose content between $18-20 \%$, as well as those for waxy cassava starches (RollandSabaté et al., 2012). This result is probably due to the fact that double helix structures in waxy starches are more organized and stable than in starches containing amylose (Rolland-Sabaté et al., 2012).

The thermal behavior was influenced by the moisture content studied in the interval $[8,50 \% \mathrm{w} / \mathrm{w}]$. As expected, thermograms presented, a decrease in the melting temperature of crystallites, when the water volumetric fraction increased (Figure 2A and $B$ for cassava and maize, respectively). The main factor increasing $T_{m}$ is a reduction of the free water available. The level of energy necessary to break the crystalline structure, therefore, increases considerably (Schirmer, Jekle, \& Becker, 2015).

For WXCS at low moisture content (e.g. v < 0.20) only one endotherm (called P2) can be observed. When the water volume was incremented, multiple melting profiles (P1 and P2) were present, implying that they respond in different forms according to the starch-water system (Figure 2A). The Flory-Huggins equation (Biliaderis, Page, \& Maurice, 1986; Farhat \& Blanshard, 1997) was used to model the effect of water content over melting temperature $T_{m}$ :

$$
\frac{1}{T_{m}}-\frac{1}{T_{m}^{0}}=\left(\frac{R}{\Delta H_{u}}-\frac{V_{2}}{V_{1}}\right)\left[V_{1}-\chi_{12} v_{1}^{2}\right]
$$


Where $T_{m}^{0}$ is the equilibrium melting point of anhydrous starch; $R$ is the gas constant; $H_{u}$ is the polymer melting heat; $V_{1}$ and $V_{2}$ are the molar volumes of solvent (water) and polymer, respectively; $U_{1}$ is the volumetric fraction of solvent; ${ }_{12}$ is the Flory-Huggins interaction parameter, $T_{m}^{0}$ and ${ }_{12}$ were obtained by minimization. (Garcia et al., 1996)

The plot of $1 / \mathrm{Tm}$ as a function of $U_{1}$ confirmed the fit between our experimental data and the model (Figure 3). Our data also matched with previous works (Barron 1999; Garcia et al. 1996).

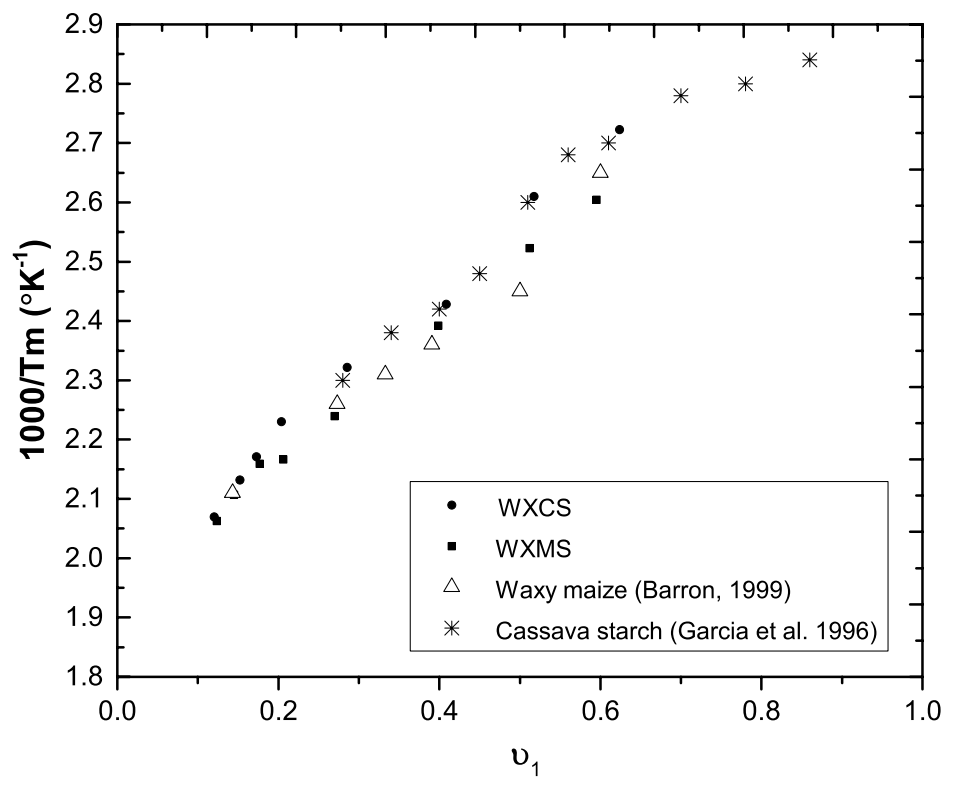

Figure 3. Plot of melting data according to the Flory-Huggins equation for the determination of $T_{m}^{0}$ (computed from the intercept at volumetric fraction $\mathrm{U}_{1}=0$ ).

Table 1. Parameters of the Flory-Huggins model

\begin{tabular}{ccccccc}
\hline Starch & \multicolumn{2}{c}{ Parameters } & \multicolumn{3}{c}{ Quality Parameter fitting } \\
\hline & $T_{m}^{0}\left({ }^{(} \mathrm{C}\right)$ & $\Delta \mathrm{H}_{\mathrm{u}}\left({\left.\mathrm{Kj} . \mathrm{mol}^{-1}\right)}^{-1}\right.$ & $\chi_{12}$ & $\mathrm{R}^{2}$ & $\mathrm{SEE}$ & $\mathrm{RSD}$ \\
\hline WXCS & $256.2(0.0)^{*}$ & $34.6(0.15)$ & 0.34 & 0.99 & 0.03 & 0.41 \\
WXMS & $246.0(0.0)$ & $47.6(0.16)$ & 0.12 & 0.99 & 0.07 & 0.87 \\
\hline
\end{tabular}

${ }^{*}$ Standard deviations are given in parentheses.

The experimental data show a high correlation $\left(R^{2}\right)$ (Table 1$)$ between water volumetric fraction and $T_{m}$ for the range studied $(0.10-0.60)$. The low SEE and 
RSD values indicate that the Flory-Huggins equation can be reliably used to describe the melting behavior of WXCS and WXMS. The parameter ${ }_{12}$ shows that the WXMS-water system (0.12) is more stable and homogeneous than WXCS (0.34).

The behavior of both water-starch systems (WXCS and WXMS) was similar to those reported for potato (Donovan, 1979), cassava (Garcia et al., 1996), rice (Biliaderis, Page, Maurice, et al., 1986) and waxy maize starches (Liu, Xie, Yu, \& Chen, 2006). Two endotherms (P1 and P2) for water volumetric fractions between 0.45 and 0.60 can be observed. These transitions reflect the fusion of organized domains of amylopectin chains. Some authors have attributed the first transition (P1) to a destabilization of crystallite-containing granules by the stress created from the adjacent amorphous region which is hydrated and fully swollen (Donovan, 1979). In other words, after melting, the polysaccharides in the amorphous region absorb the available water which is then less available for the remaining nongelatinized granules. The effective water concentration is further reduced and, consequently, the gelatinized granules melt at even higher temperatures thus originating a second transition (P2) in agreement with the polymer-diluent interactions theory (Biliaderis, Page, Maurice, et al., 1986).

The $T_{m}^{0}$ value for WXCS was $256^{\circ} \mathrm{C}$ (Table 1 ), similar to the values reported for cassava starch with amylose $\left(254^{\circ} \mathrm{C}\right.$ ) (Garcia et al. 1996), waxy rice starch (252 $\left.{ }^{\circ} \mathrm{C}\right)$ (Biliaderis, Page, Maurice, et al., 1986), and higher than potato starch (221.5 ${ }^{\circ} \mathrm{C}$ ), oatmeal $\left(214^{\circ} \mathrm{C}\right)$ and wheat $\left(291^{\circ} \mathrm{C}\right)$ (Núñez et al., 2009). The $\Delta \mathrm{H}_{\mathrm{u}}$ for WXCS (Table 1) was slightly lower than normal cassava starch (38.2 kJ.mol$\left.{ }^{-1}\right)$ and higher than rice, potato, and oatmeal. Predicted $\Delta \mathrm{H}_{\mathrm{u}}$ for WXMS $\left(47.6 \mathrm{~kJ}^{-\mathrm{mol}^{-1}}\right)$ was superior to WXCS $\left(34.6 \mathrm{~kJ}^{\mathrm{mol}}{ }^{-1}\right)$ probably because of its more stable crystalline structure. It has been reported that the size, crystallites perfection and amorphous zones have an impact on the thermal stability (Biliaderis, 2009). WXMS melting temperature associated to $T_{e}$ or temperature where the endotherm ends are a bit higher than for WXCS (Figure 1B), due probably to the fact that WXMS only 
contains crystal structures type $A$, which are more stable and have a higher $T_{m}$ compared with the polymorphous structures type B present in WXCS.

\subsection{Glass transition}

3.3.1 Differential scanning calorimetry (DSC)

For both WXCS and WXMS, $T_{g}$ decreased with increasing moisture contents (Figure 4A), as predicted by the plasticizing effect of water (Kalichevsky et al., 1992; Bizot et al., 1997; Chaudhary et al., 2011).

The presence of mobile water molecules has been evidenced by Nuclear Magnetic Resonance (NMR) on starch chains at $14-17 \%$ moisture content (w.b.) for cassava and potato starches, demonstrating the beginning of the plasticization (Chatakanonda, Dickinson, \& Chinacohoti, 2003). The Couchman-Karasz model was applied to the DSC data to predict the water effect on the glass transition temperature (Figure 4B) (Bizot et al., 1997; Y. H. Roos, 1995):

$$
T g=\frac{w_{1} C_{p}+w_{2} C_{p_{2}} T_{g_{2}}}{w_{1} C_{p_{1}}+w_{2} C_{p_{2}}}
$$

Where, $W_{1}, W_{2}$ : mass fractions, $T_{g 1}, T_{g 2}$ : glass transitions temperatures, $\Delta \mathrm{Cp}_{1}$, $\Delta \mathrm{Cp}_{2}$ : heat capacity change, in this case, for pure starch and water respectively. The regression parameters for the anhydrous $T_{g}$ of WXCS and WXMS were comparable (Figure 4B), with $\mathrm{T}_{\mathrm{g}}$ (anhydrous) $=189.7 \pm 19.7^{\circ} \mathrm{C}$ and $\Delta \mathrm{Cp}=0.43 \pm$ $0.06 \mathrm{~J} \mathrm{~g}^{-1} \mathrm{~K}^{-1}$ for WXCS $\left(\mathrm{R}^{2}=0.96\right)$; and $\mathrm{T}_{\mathrm{g}}$ (anhydrous) $=197.5 \pm 31.5^{\circ} \mathrm{C}$ and $\Delta \mathrm{Cp}$ $=0.44 \pm 0.10 \mathrm{~J} \mathrm{~g}^{-1} \mathrm{~K}^{-1}$ for WXMS $\left(R^{2}=0.93\right)$.

The values of anhydrous $\mathrm{T}_{\mathrm{g}}$ (Figure 4B) were lower than that reported by Orford et al., (1989) for waxy maize starch starch $\left(227 \pm 10^{\circ} \mathrm{C}\right)$ but slightly higher than the one presented for cassava starch (Sandoval, 2006) (183.8 and $171.8{ }^{\circ} \mathrm{C}$ ) Biliaderis (2009) established a $\mathrm{Tg}$ range between 225 and $235{ }^{\circ} \mathrm{C}$ for anhydrous starch. The variability of these results may stem from differences in the source of starch (de 
Graaf, Karman, \& Janssen, 2003), or also from the sensitivity of the extrapolations of anhydrous $T_{g}$ to experimental conditions.
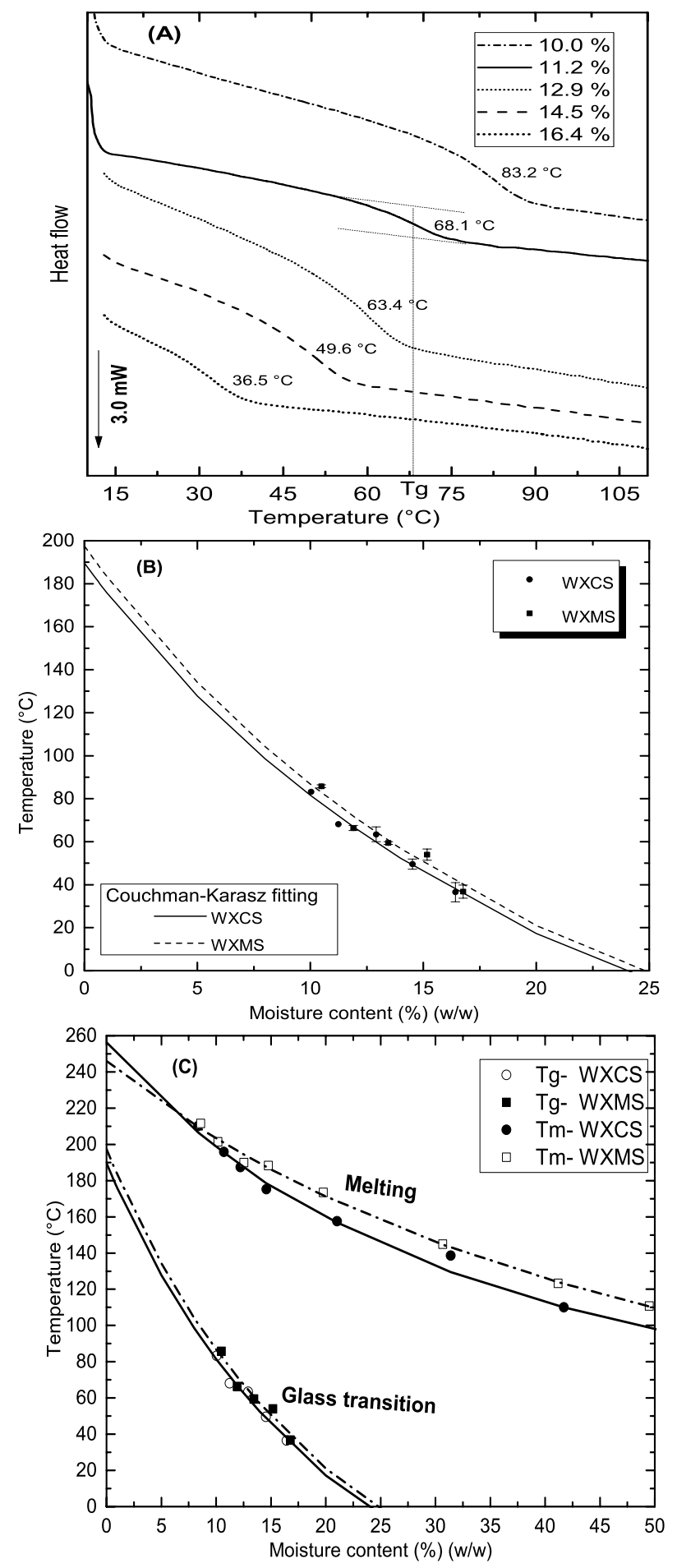

Figure 4. (A) WXCS Thermograms at different water contents $(\% \mathrm{w} / \mathrm{w})$; (B) Couchman-Karasz model fitting for the glass transition temperatures and (C) Waxy cassava starch (WXCS) and waxy maize starch (WXMS) state diagrams. 
Similarly, the $\Delta \mathrm{Cp}$ values observed agree with those reported in previous studies (Kalichevsky et al., 1993; Orford et al., 1989; van der Sman \& Meinders, 2011; Zimeri \& Kokini, 2003). The experimental and extrapolated values of $T_{g}$ for WXCS and WXMS were comparable and no significant differences were found between them, which may be related to the similarities in the structure of amylopectin chains reported by Rolland-Sabaté et al., (2012).

WXCS and WXMS state diagrams obtained with the Flory-Huggins and Couchman-Karasz models are presented on Figure $4 \mathrm{C}$. This is a useful information for processes such as extrusion, where moisture content and temperature, and hence glass transition and rubber modulus, represent key control factors for the expansion phenomenon that occurs at the extruder die when the material acquires its texture.

\subsubsection{Dynamic Mechanical Thermal Analysis (DMTA)}

The glass transition temperature, measured as $T_{\alpha}$, increased in both starch sources as moisture content decreased in the water-starch systems. This is a typical relaxation behavior when the plasticizing effect changes. Similar results have been reported in maize starch and amylopectin with multiple crystallinity degrees (Kalichevsky, Jaroszkiewicz, Ablett, Blanshard, \& Lillford, 1992).

In this study $\mathrm{T}_{\alpha}$ DMTA values were 10 to $20^{\circ} \mathrm{C}$ higher than those reported by Kalichevsky et al. (1992). This result may indicate that some moisture loss occurred even though the samples were protected with Teflon ${ }^{\circledR}$ grease.

The $T_{\alpha}$ measured by DMTA $\left(90-100^{\circ} \mathrm{C}\right)$ were also higher than the $T_{g}$ obtained by DSC. Kalichevsky et al. (1992) made a similar observation and suggested the difference is related to the frequency of the measurements: Static measurement in the case of DSC, and dynamic $(1 \mathrm{~Hz})$ in the case of DMTA. 


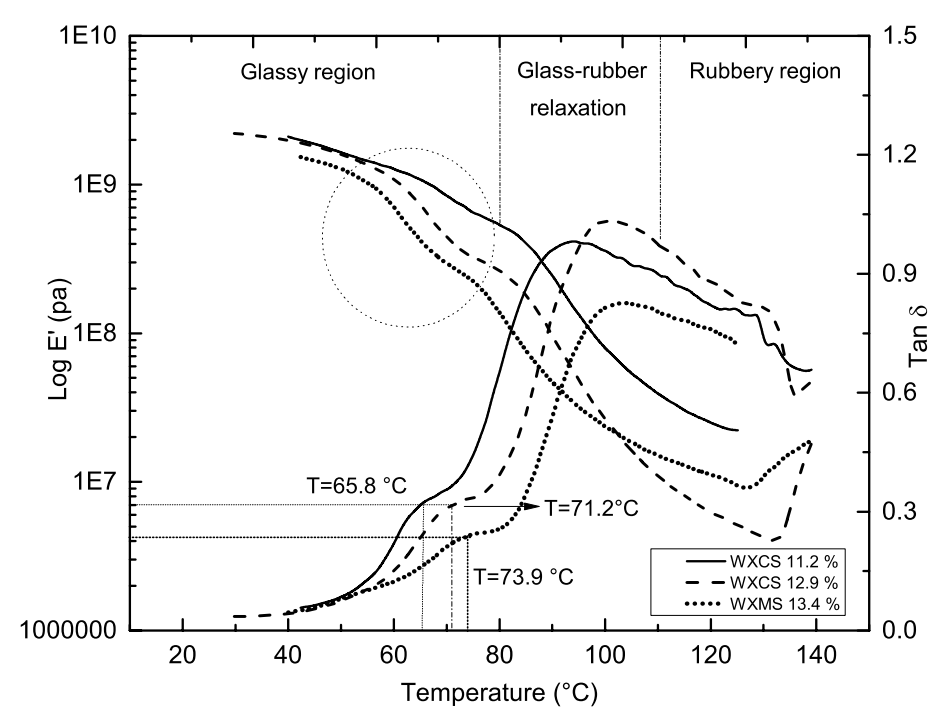

Figure 5. DMTA curves obtained at different moisture contents $(\% \mathrm{w} / \mathrm{w})$ for amorphous WXCS and WXMS.

Curves of $\tan \delta$ for amorphous WXCS (11.2 $-12.9 \% \mathrm{w} / \mathrm{w})$ and WXMS $(13.4 \% \mathrm{w} / \mathrm{w})$, displayed a small initial transition in the range $65.8-73.9^{\circ} \mathrm{C}$ (Figure 5). At higher moisture contents, the same phenomenon was observed, but with less reproducibility.

$T_{\alpha}$ values at different water contents (Figure 6) were fitted with the Gordon-Taylor model to predict anhydrous $T_{g}$ (noted $T_{g_{1}}$ ) of WXCS and WXMS:

$$
T_{g}=\frac{W_{1} T_{g 1}+K W_{2} T_{g 2}}{W_{1}+K W_{2}}
$$

Where, $W_{1}, W_{2}$ : mass fractions and $T_{g 1}, T_{g 2}$ : glass transitions temperatures of pure starch and water respectively, $\mathrm{K}$ is a constant. All the temperatures are expressed in Kelvins (Roos, 1995). 


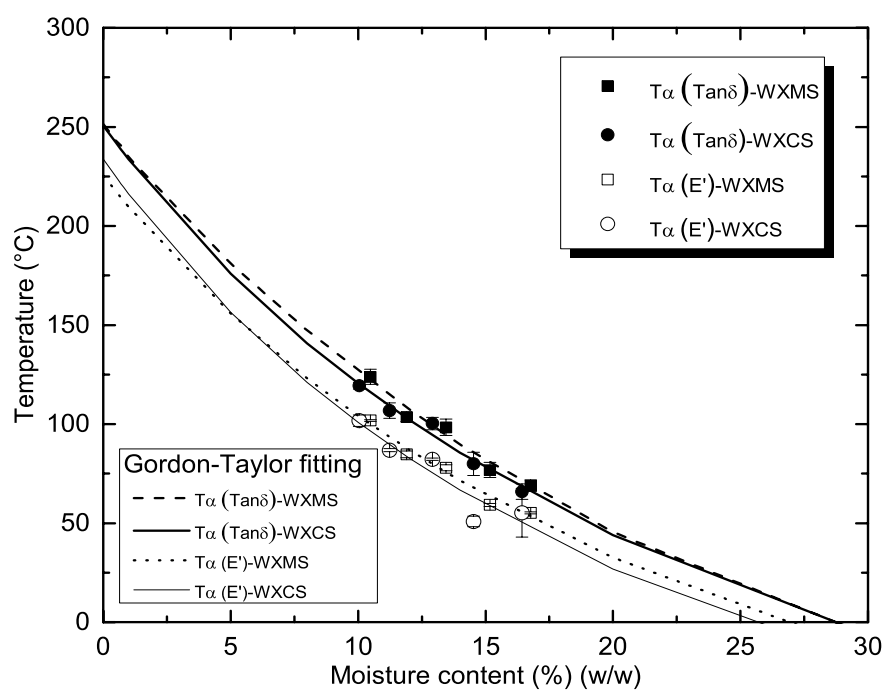

Figure 6. Mechanical relaxation temperatures $\left(T_{\alpha}\right)$ of WXCS and WXMS (amorphous state) as a function of the water content (\% w/w).

The $T_{g 1}$ (Table 2) of WXCS as WXMS (anhydrous state) were close to those reported by Roos and Karel (1991) for wheat starch $\left(243^{\circ} \mathrm{C}\right)$ and lower than those reported for wheat, maize, and rice extrudates $\left(281^{\circ} \mathrm{C}\right)$ by Bindzus et al. (2002). $\mathrm{T}_{\alpha}$ $(\tan \delta)$ and $\mathrm{T}_{\alpha}\left(\mathrm{E}^{\prime}\right)$ values obtained were between $29-38^{\circ} \mathrm{C}$ and $16-18{ }^{\circ} \mathrm{C}$ greater than $T_{g}$ measured by DSC. The $T_{\alpha}\left(E^{\prime}\right)$ were similar to the ones found for cassava starch with $38 \pm 1 \%$ crystallinity (Perdomo et al., 2009) and cassava starch films (Chang, Cheah, \& Seow, 2000), which may be due to partial starch retrogradation in the films during their equilibration with salt solutions.

Table 2. Gordon - Taylor parameters for amorphous WXCS and WXMS.

\begin{tabular}{ccccc}
\hline \multirow{2}{*}{ Starch } & & \multicolumn{2}{c}{ Parameters } & Fitting \\
\cline { 2 - 5 } & & $\mathbf{K}$ & $\mathbf{T g}_{1}\left({ }^{\circ} \mathbf{C}\right)$ & $\mathbf{R}^{2}$ \\
\hline \multirow{2}{*}{ WXCS } & $\tan \delta$ & $4.51 \pm 0.70$ & $250.6 \pm 24$ & 0.97 \\
& $\mathrm{E}^{\prime}$ & $4.99 \pm 1.91$ & $233.6 \pm 59$ & 0.83 \\
WXMS & $\tan \delta$ & $4.94 \pm 0.74$ & $251.4 \pm 26$ & 0.96 \\
& $\mathrm{E}^{\prime}$ & $4.49 \pm 0.76$ & $225.5 \pm 25$ & 0.96 \\
\hline
\end{tabular}


The value of the $\mathrm{K}$ parameter depends on the change in the thermal expansion coefficient $(\alpha)$ as the glass transition occurs. The values found in this study are close to the ones reported by Roos y Karel (1991) in wheat $(K=5.2)$ and pea starches $(K=4.28 \pm 1.46)$ for binary starch-water systems (Pelgrom, Schutyser, \& Boom, 2012).

\section{Conclusions}

The thermal analysis developed for WXCS and WXMS gave consistent results with other studies performed for cassava, maize, potato and rice starches. Independent of the amylose content, the crystallite melting temperature has an inverse relationship with the water volumetric fraction. The WXCS endothermic transitions can be described through the Flory-Huggins model due to the high $\mathrm{R}^{2}$, and low SEE, RSD values. $T_{\alpha}$ changes with moisture content are explained with the plasticizing effect of water on WXCS. Variability was found in the glass transition temperature of anhydrous starches, confirming the water distribution complexity within the amorphous and crystalline domains. WXCS exhibited a thermal behavior similar to WXMS. A state diagram was obtained for WXCS an important tool in thermal processes such as extrusion. The diagram allows exploring new potential uses of this new starch in the food or materials industry.

\section{Acknowledgements}

We acknowledge M. De Carvalho and Jean-Eudes Maigret, Roselyne Desirest (Research Unit on Biopolymers, Interactions and Assemblies, INRA, Nantes, France) for excellent advising and technical support. Field assistance provided by Nelson Morante and Fernando Calle and the extraction of WXCS extraction coordinated by John Belalcazar supervisor of the root quality laboratory at CIAT are greatly appreciated. 


\section{Funding}

This work was supported by the CIAT Cassava Project, which is part of and funded by the CGIAR Research Program on Roots, Tubers and Bananas (RTB) with support from CGIAR Fund Donors. http://www.cgiar.org/about-us/governing-2010june-2016/cgiar-fund/fund-donors-2/

Research was conducted under the framework of a Memorandum of Agreement between CIAT, CIRAD/INRA and Univalle. The Administrative Department of Science, Technology and Innovation (COLCIENCIAS) supported this work through the doctoral scholarships program in Colombia. 


\section{Bibliography}

Abiad, M. G., Carvajal, M. T., \& Campanella, O. H. (2009). A Review on Methods and Theories to Describe the Glass Transition Phenomenon: Applications in Food and Pharmaceutical Products. Food Engineering Reviews, 1(2), 105-132.

Barron, C. (1999). Déstructuration d'amidons peu hydratés sous cisaillement. Thèse de Doctorat, Ecole Doctorale Sciences pour l'ingénieur de Nantes. France.

Biliaderis, C. G. (1991). The structure and interactions of starch with food constituents. Canadian Journal of Physiology and Pharmacology, 69(1), 60-78.

Biliaderis, C. G. (2009). Chapter 8 - Structural Transitions and Related Physical Properties of Starch. In J. BeMiller \& R. Whistler (Eds.), Starch (Third Edition) (pp. 293-372). San Diego: Academic Press

Biliaderis, C. G., Page, C. M., \& Maurice, T. J. (1986). On the multiple melting transitions of starch/monoglyceride systems. Journal of Agricultural and Food Chemistry, 22(4), 279-295.

Biliaderis, C. G., Page, C. M., Maurice, T. J., \& Juliano, B. O. (1986). Thermal characterization of rice starches: a polymeric approach to phase transitions of granular starch. Journal of Agricultural and Food Chemistry, 34(1), 6-14.

Bindzus, W., Livings, S. J., Gloria-Hernandez, H., Fayard, G., van Lengerich, B., \& Meuser, F. (2002). Glass Transition of Extruded Wheat, Corn and Rice Starch. Starch - Stärke, 54(9), 393-400.

Bizot, H., Le Bail, P., Leroux, B., Davy, J., Roger, P., \& Buleon, A. (1997). Calorimetric evaluation of the glass transition in hydrated, linear and branched polyanhydroglucose compounds. Carbohydrate Polymers, 32(1), 33-50.

Blanshard, J. M. V. (1995). The glass transition, its nature and significance in food processing. In S. T. Beckett (Ed.), Physico-Chemical Aspects of Food Processing (pp. 17-48). Boston, MA: Springer US.

Breuninger, W. F., Piyachomkwan, K., \& Sriroth, K. (2009). Chapter 12 - Tapioca/Cassava Starch: Production and Use. In B. James \& W. Roy (Eds.), Starch (Third Edition) (pp. 541-568). San Diego: Academic Press

Cai, L., \& Shi, Y.-C. (2010). Structure and digestibility of crystalline short-chain amylose from debranched waxy wheat, waxy maize, and waxy potato starches. Carbohydrate Polymers, 79(4), 1117-1123.

Ceballos, H., Sánchez, T., Morante, N., Fregene, M., Dufour, D., Smith, A. M., Mestres, C. (2007). Discovery of an Amylose-free Starch Mutant in Cassava (Manihot esculenta Crantz). Journal of Agricultural and Food Chemistry, 55(18), 7469-7476. 
Chang, Y. P., Cheah, P. B., \& Seow, C. C. (2000). Plasticizing-Antiplasticizing Effects of Water on Physical Properties of Tapioca Starch Films in the Glassy State. Journal of Food Science, 65(3), 445-451.

Chatakanonda, C., Dickinson, L., \& Chinacohoti, P. (2003). Mobility and distribution of water in cassava and potato starches by $\mathrm{H}$ and $\mathrm{H}$ NMR. Journal of Agricultural and Food Chemistry, 51, 7445-7449.

Chaudhary, D. S., Adhikari, B. P., \& Kasapis, S. (2011). Glass-transition behaviour of plasticized starch biopolymer system - A modified Gordon-Taylor approach. Food Hydrocolloids, 25(1), 114-121.

Cheetham, N. W. H., \& Tao, L. (1998). Variation in crystalline type with amylose content in maize starch granules: an X-ray powder diffraction study. Carbohydrate Polymers, 36(4), 277-284.

Chung, H.-J., \& Lim, S.-T. (2004). Physical aging of glassy normal and waxy rice starches: thermal and mechanical characterization. Carbohydrate Polymers, 57(1), 15-21.

Contreras-Gallegos, E., Domínguez-Pachecho, A., Hernández -Aguilar, E., \& CarballoCarballo, A. (2015). Study of Thermal and Structural Properties of Starch Granules from Different Maize Genotypes. J Food Biophysics, 10, 19-24.

Cruz-Orea, A., Pitsi, G., Jamée, P., \& Thoen, J. (2002). Phase Transitions in the Starch-Water System Studied by Adiabatic Scanning Calorimetry. J Agric Food Chem, 50, 1335-1344.

Da G., Dufour D., Giraldo A., Moreno M., Tran Th., Velez G., Sanchez T., Le Thanh M., Marouzé C., \& Maréchal P.A. (2013). Cottage level cassava starch processing systems in Colombia and Vietnam. Food and Bioprocess Technology, 6(8), 22132222.

de Graaf R. A., Karman A. P., \& Janssen L. P. B.M (2003), Material properties and glass transition temperatures of different thermoplastic starches after extrusion processing. Starch/Stärke, 55, 80-86

Donovan, J. W. (1979). Phase transitions of the starch-water system. Biopolymers, 18(2), 263-275.

Farahnaky, A., Farhat, I. A., Mitchell, J. R., \& Hill, S. E. (2009). The effect of sodium chloride on the glass transition of potato and cassava starches at low moisture contents. Food Hydrocolloids, 23(6), 1483-1487.

Farhat, I. A., \& Blanshard, J. M. (1997). On the extrapolation of the melting temperature of dry starch from starch-water data using the Flory-Huggins equation. Carbohydrate Polymers, 34(4), 263-265.

García, N. L., Famá, L., Dufresne, A., Aranguren, M., \& Goyanes, S. (2009). A comparison between the physico-chemical properties of tuber and cereal starches. Food Research International, 42(8), 976-982. 
Garcia, V., Colonna, P., Lourdin, D., Buleon, A., Bizot, H., \& Ollivon, M. (1996). Thermal transitions of cassava starch at intermediate water contents. Thermal Analysis, 47, 1213-1228.

Gomand, S. V., Lamberts, L., Derde, L. J., Goesaert, H., Vandeputte, G. E., Goderis, B., Delcour, J. A. (2010). Structural properties and gelatinisation characteristics of potato and cassava starches and mutants thereof. Food Hydrocolloids, 24(4), 307317.

Guo, L., Liang, Q., \& Du, X. (2011). Effects of molecular characteristics of tea polysaccharide in green tea on glass transitions of potato amylose, amylopectin and their mixtures. Food Hydrocolloids, 25(3), 486-494.

Hizukuri, S. (1985). Relationship between the distribution of the chain length of amylopectin and the crystalline structure of starch granules. Carbohydrate Research, 141(2), 295-306.

Hizukuri, S., Kaneko, T., \& Takeda, Y. (1983). Measurement of the chain length of amylopectin and its relevance to the origin of crystalline polymorphism of starch granules. Biochimica et Biophysica Acta (BBA) - General Subjects, 760(1), 188191.

Homer, S., Kelly, M., \& Day, L. (2014). Determination of the thermo-mechanical properties in starch and starch/gluten systems at low moisture content - A comparison of DSC and TMA. Carbohydrate Polymers, 108(0), 1-9.

Kalichevsky, M. T., Jaroszkiewicz, E. M., Ablett, S., Blanshard, J. M. V., \& Lillford, P. J. (1992). The glass transition of amylopectin measured by DSC, DMTA and NMR. Carbohydrate Polymers, 18(2), 77-88.

Kalichevsky, M. T., Jaroszkiewicz, E. M., \& Blanshard, J. M. V. (1993). A study of the glass transition of amylopectin-sugar mixtures. Polymer, 34(2), 346-358.

Koehorst-van Putten, H. J. J., Sudarmonowati, E., Herman, M., Pereira-Bertram, I. J., Wolters, A. M. A., Meima, H., Visser, R. G. F. (2012). Field testing and exploitation of genetically modified cassava with low-amylose or amylose-free starch in Indonesia. Transgenic Research, 21(1), 39-50.

Lelievre, J. (1974). Starch gelatinization. Journal of Applied Polymer Science, 18(1), 293296.

Liu, H., Xie, F., Yu, L., \& Chen, L. (2006). Gelatinization of cornstarch with different amylose/amylopectin content. Carbohydrate Polymers, 65, 357-363.

Moorthy, S. N. (2004). 11 - Tropical sources of starch. In A.-C. Eliasson (Ed.), Starch in Food (pp. 321-359): Woodhead Publishing

Morante, N., H. Ceballos, T. Sánchez, A. Rolland-Sabaté, F. Calle, C. Hershey, O. Gibert, \& D. Dufour (2016). Discovery of new spontaneous sources of amylose-free cassava starch and analysis of their structure and techno-functional properties. Food Hydrocolloids 56: 383-395. 
Nara, S., \& Komiya, T. (1983). Studies on the Relationship Between Water-satured State and Crystallinity by the Diffraction Method for Moistened Potato Starch. Starch Stärke, 35(12), 407-410.

Núñez, M., Sandoval, A., Müller, A., Della Valle, G., \& Lourdin, D. (2009). Thermal Characterization and Phase Behavior of a Ready-to-Eat Breakfast Cereal Formulation and its Starchy Components. Food Biophysics, 4(4), 291-303.

Nuwamanya, E., Baguma, Y., Emmambu, E., \& Patrick, R. (2009). Crystalline and pasting properties of cassava starch are influenced by its molecular properties. African Journal of Food Science, 4(1), 008-015.

Orford, P. D., Parker, R., Ring, S. G., \& Smith, A. C. (1989). Effect of water as a diluent on the glass transition behaviour of malto-oligosaccharides, amylose and amylopectin. International Journal of Biological Macromolecules, 11(2), 91-96.

Pelgrom, P. J. M., Schutyser, M. A. I., \& Boom, R. M. (2012). Thermomechanical Morphology of Peas and Its Relation to Fracture Behaviour. Food and Bioprocess Technology, 6(12), 3317-3325.

Perdomo, J., Cova, A., Sandoval, A. J., García, L., Laredo, E., \& Müller, A. J. (2009). Glass transition temperatures and water sorption isotherms of cassava starch. Carbohydrate Polymers, 76(2), 305-313.

Rolland-Sabaté, A., Sanchez, T., Buléon, A., Colonna, P., Ceballos, H., Zhao, S.-S., Dufour, D. (2013). Molecular and supra-molecular structure of waxy starches developed from cassava (Manihot esculenta Crantz). Carbohydrate Polymers, 92(2), 1451-1462.

Rolland-Sabaté, A., Sánchez, T., Buléon, A., Colonna, P., Jaillais, B., Ceballos, H., \& Dufour, D. (2012). Structural characterization of novel cassava starches with low and high-amylose contents in comparison with other commercial sources. Food Hydrocolloids, 27(1), 161-174.

Roos, Y., \& Karel, M. (1991). Water and Molecular Weight Effects on Glass Transitions in Amorphous Carbohydrates and Carbohydrate Solutions. Journal of Food Science, 56(6), 1676-1681.

Roos, Y. H. (1995). Phase Transitions in Foods. New York: Academic Press.

Roos, Y. H., \& Jouppila, K. (2003). Plasticization Effect of Water on Carbohydrates in Relation to Crystallization. In G. Kaletunç \& K. Breslauer (Eds.), Characterization of Cereals and Flours. New York Basel

Sánchez, T., Mafla, G., Morante, N., Ceballos, H., Dufour, D., Calle, F., Moreno, X., Pérez, J. C., \& Debouck, D. (2009). Screening of starch quality traits in cassava (Manihot esculenta Crantz). Starch/Stärke, 61, 12-19. Erratum: (2009) Starch/Stärke, 61, 310.

Sandoval, A.J., Nuñez, M., Müller, A.J., Della Valle, G., \& Lourdin, D. (2009). Glass transition temperatures of a ready to eat breakfast cereal formulation and its main 
components determined by DSC and DMTA. Carbohydrate Polymers, 76 (4), 528534.

Savitzky, A \& M.J.E. Golay (1964). Smoothing and differentiation of data by simplified least squares procedures. Anal. Chem., 36 (8),1627-1639

Schirmer, M., Jekle, M., \& Becker, T. (2015). Starch gelatinization and its complexity for analysis. Starch - Stärke, 67(1-2), 30-41.

Slade, L., \& Levine, H. (1993). The Glassy State Phenomenon n Food Molecules. In J. M. Blanshard \& P. J. Lillford (Eds.), The Glassy State in Foods (pp. 35-101)

Tran T., Da G., Moreno-Santander M. A., Vélez-Hernández G. A., Giraldo-Toro A., Piyachomkwan K., Sriroth K., Dufour D. (2015). A comparison of energy use, water use and carbon footprint of cassava starch production in Thailand, Vietnam and Colombia. Resources, Conservation and Recycling, 100, 31-40.

van den Berg, C. (1981). Vapour sorption equilibria and other water-starch interaction; a physico-chemical approach. Ph.D. Thesis, Agricultural Univ, Wageningen, The Netherlands. $186 \mathrm{p}$.

Van der Sman, R. G. M., \& Meinders, M. B. J. (2011). Prediction of the state diagram of starchwater mixtures using the Flory-Huggins free volume theory. Soft Matter, $7(2), 429-442$.

Wang, T. L., Bogracheva, T. Y., \& Hedley, C. L. (1998). Starch: as simple as A, B, C? Journal of Experimental Botany, 49(320), 481-502.

Xue, T., Yu, L., Xie, F., Chen, L., \& Li, L. (2008). Rheological properties and phase transition of starch under shear stress. Food Hydrocolloids, 22(6), 973-978.

Zeleznak, K. J., \& Hoseney, R. C. (1987). The glass transition in starch Cereal Chemistry(64), 121-124.

Zhao, S.-S., Dufour, D., Sánchez, T., Ceballos, H., \& Zhang, P. (2011). Development of waxy cassava with different Biological and physico-chemical characteristics of starches for industrial applications. Biotechnology and Bioengineering, 108(8), 1925-1935.

Zimeri, J. E., \& Kokini, J. L. (2003). Phase transitions of inulin-waxy maize starch systems in limited moisture environments. Carbohydrate Polymers, 51(2), 183-190.

Zobel, H. F. (1988). Starch Crystal Transformations and Their Industrial Importance. Starch - Stärke, 40(1), 1-7. 